\title{
BONE TISSUE ENGINEERING USING B- TRICALCIUM PHOSPHATE SCAFFOLDS FABRICATED VIA SELECTIVE LASER SINTERING
}

\author{
Baigong Ma, Liulan Lin, Xianxu Huang, Qingxi Hu, Minglun Fang \\ Rapid Manufacturing Engineering Center Shanghai University, Shanghai University, \\ China;Email:huqingxi@mail.shu.edu.cn
}

\begin{abstract}
TCP})$ is a biodegradable ceramic with potential application for bone replacement. In this work, porous $\beta$-TCP scaffolds were fabricated via selective laser sintering, which is a rapid prototyping technique. B -TCP and glue composite was developed as a powder material to product porous scaffolds, using this computer-controlled sintering and deposition process. The $\beta$-TCP scaffolds were produced with the strut size $800 \mu \mathrm{m}$ and max porosity $55.4 \%$. Compressive modulus ranged from $13 \mathrm{MPa}$ to $18 \mathrm{Mpa}$, and shrinkage was about $26 \%$. Analysis of the measured data shows a high correlation between the scaffold porosity and the compressive properties based on SLS process relationship.
\end{abstract}

Key words: bone tissue engineering, rapid prototyping, $\beta$ - tricalcium phosphate, bionic scaffolds, porosity

\section{INTRODUCTION}

Scaffold-guided tissue engineering (TE) has been developed to regenerate specific and functional human tissues or organs ${ }^{[1,2]}$. In view of bone tissue engineering, the bone substitute must have proper pore and porosity for bone repair so as to accelerate bone regeneration ${ }^{[3]}$. TE scaffolds should facilitate the colonization of cells and possess characteristics that enhance cell attachment, proliferation, migration and expression of native phenotypes. Scaffold characteristics and properties such as porosity, surface area to volume ratio, pore size, pore interconnectivity, structural strength, shape (or overall geometry) and biocompatibility are often considered to be critical factors in their design and fabrication ${ }^{[4]}$. It may be best achieved by

This project is supported by the Shanghai Education Foundation of China under the grant No. 05A281.

Please use the following format when citing this chapter:

Ma, Baigong, Lin, Liulan, Huang, Xianxu, Hu, Qingxi, Fang, Minglun, 2006, in nternational Federation for Information Processing (IFIP), Volume 207, Knowledge Enterprise: Intelligent Strategies In Product Design, Manufacturing, and Management, eds. K. Wang, Kovacs G., Wozny M., Fang M., (Boston: Springer), pp. 710-716. 
combining image-based computational design techniques and solid free-form fabrication (SFF) methods.

Selective laser sintering (SLS) is one of SFF method. SLS constructs scaffolds from 3-D digital data by sequentially fusing regions in a powder bed, layer by layer, and then the laser beam is selectively scanned over the powder, causes the particles to be fused together to form a solid mass ${ }^{[5,6]}$. SLS is a well-adapted technology, this makes it fast and cost effective to fabricate tissue engineering scaffolds ${ }^{[7,8]}$. We have employed SLS to create $\beta$-TCP scaffolds.

$\beta$ - TCP is an important biodegradable ceramic material and has been subjected to intensive studies, which has potential application for bone replacement. But this material cannot be sintered directly by the laser, here epoxy and nylon was used binder. The work presented here is part of results on the manufacture and characterization of $\beta$-TCP scaffolds by SLS.

First, various types of structures with different mechanical properties were constructed with a computer-aided design. Then $\beta$-TCP matrix was produced on a selective laser sintering technique. After high temperature treatment, the ceramic scaffolds were obtained with designed microporosity. The result of $\beta$-TCP scaffolds with $800 \mu_{\mathrm{m}}$ pore diameter and fully interconnected pore morphology were discussed.

\section{MATERIALS AND FABRICATION}

\subsection{Material preparation}

The bioceramic can be degraded in different degrees under the biological environment and be absorbed by organization. $\beta$-TCP powders used in this work were from shanghai tissue engineering research center. Its average particle size was $100 \mu_{\mathrm{m}}$. IT was certified that $\beta$-TCP scaffolds repair defective bone very well with compounding bone marrow matrix stem cell.

The mixture powders of epoxy resin and nylon were used as the adhesion of $\beta$-TCP powder. Epoxy resin and nylon's glass transition temperature is respectively about $65-75^{\circ} \mathrm{C}$ and $110-120^{\circ} \mathrm{C}$. Particle average size of the blending powders is $200 \mu \mathrm{m}$.

\subsection{Scaffold design}

Rectangular block porous scaffolds ( $21 \mathrm{~mm}$ length, $21 \mathrm{~mm}$ width, $5 \mathrm{~mm}$ height), with three-dimensional orthogonal periodic porous architectures, $800 \mu_{\mathrm{m}}$ in strut diameter, were designed using Unigraphics NX3 solid modeling software (UGS PLM Solutions, Plano, TX). An example was shown in Figure1. 


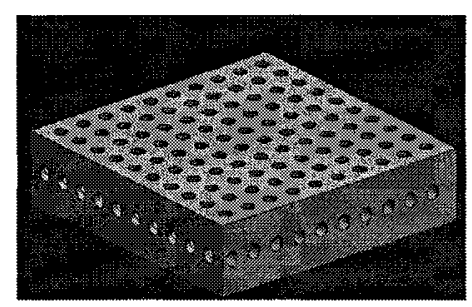

Fig. 1. Virtual structure designed with CAD

\subsection{Scaffold fabrication}

The settings for the SLS process parameters were kept at their default values except for laser power and scanning speed. Laser power was set at $10 \mathrm{~W}$. Then scaffolds were built layer-by-layer using a powder layer thickness of $0.1 \mathrm{~mm}$. It was found that part was constructed well without preheating. Different ratio mixture was subjected to laser sintering at different laser power for the optimal setting. By varying the process parameter, three groups of specimens comprising of different ratio of $\beta$ TCP/ epoxy resin and nylon were tested, the ratio was 2:1:1, 5:3:2 and $5: 2: 3$. The scaffold surface quality of ratio $5: 2: 3$ was the best, and its strength was more advanced. The specimen is shown in Figure 2(a).

Then this specimen was put into a stove (SX2-1013, Zufa Ltd. China). During the high temperature treatment, the temperature should rise step by step. It may lead to thermal expansion mismatch and a breaking structure if temperature was changed so fast. It took about 40min to elevate the temperature from room temperature to $200^{\circ} \mathrm{C}$. Then it took $800 \mathrm{~min}$ to achieve $600^{\circ} \mathrm{C}$. Above $600{ }^{\circ} \mathrm{C}$, epoxy resin and nylon were completely burnt and the sintering temperature $\left(1100{ }^{\circ} \mathrm{C}\right)$ could be reached during $250 \mathrm{~min}$. Then kept the temperature for 3 hours. A piece of the scaffold treated by high temperature was shown as figure 2 (b).

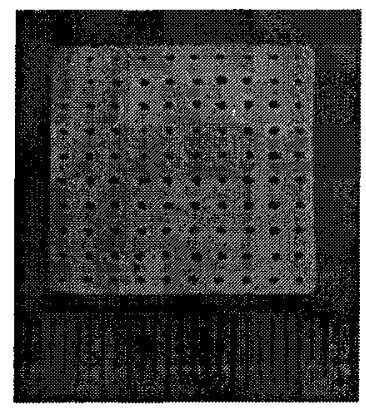

a) before high temperature treatment

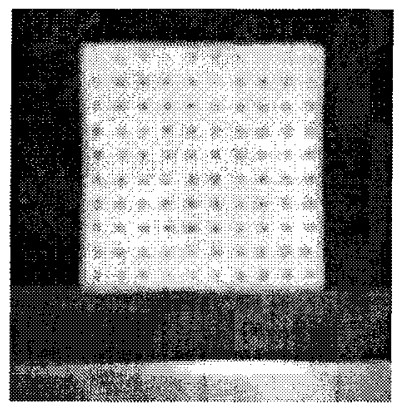

b) after high temperature treatment

Fig.2 the scaffold of laser power $10 \mathrm{w}$ with ratio $5: 2: 3$, each grid under the scaffold was $1 \mathrm{~mm}$ 


\section{RESULTS}

\subsection{Porosity and volume density of sintered specimen}

The theoretical porosity $\mathrm{P}(\%)$ was estimated based on the ratio, which the volume of the pores in the scaffold divided the whole volume of the scaffold. According to static equilibrium method in liquid each porosity value was determined as:

$$
\mathrm{P}=\left(\mathrm{V}_{1}-\mathrm{V}_{3}\right) /\left(\mathrm{V}_{2}-\mathrm{V}_{3}\right) \times 100 \%
$$

Where $\mathrm{P}(\%)$ was the porosity ratio of specimen, $\mathrm{V}_{1}(\mathrm{ml})$ was the volume of ethanol in the measuring cylinder, $V_{2}(\mathrm{ml})$ was the volume of ethanol after the specimen saturated by the ethanol, $V_{3}(\mathrm{ml})$ was the volume of ethanol after taking out the specimen.

Table 1 the porosity of scaffold

\begin{tabular}{cccc}
\hline Parameters & Specimen 1 & Specimen 2 & Specimen 3 \\
\hline $\mathrm{W}(\mathrm{g})$ & 0.2 & 0.2 & 0.1 \\
\hline $\mathrm{V}_{1}\left(\mathrm{~cm}^{3}\right)$ & 38.25 & 13.92 & 20.00 \\
\hline $\mathrm{V}_{2}\left(\mathrm{~cm}^{3}\right)$ & 33.90 & 9.71 & 16.00 \\
\hline $\mathrm{V}_{3}\left(\mathrm{~cm}^{3}\right)$ & 33.82 & 9.60 & 15.90 \\
\hline $\mathrm{P}(\%)$ & 55.375 & 39.27 & 41.00 \\
\hline
\end{tabular}

From table 1 it was found that the porosity of scaffold ranged from $39.27 \%$ to $55.375 \%$ with laser power changing. It is to say, more higher porosity can be arrived with changing the process characters.

\subsection{Microstructure analysis}

Microstructure characterization of the SLS-fabricated $\beta$-TCP scaffold specimens were carried out using a scanning electron microscope (SEM, JEOL JSM-6700F, Japan) to analyze the surface morphology and microstructure of the sintered specimen.

Figure 3(a) shows that the bigger pores of the $\beta$-TCP specimen are surrounded by innumerable micro-pores. And the diameter of the macropores is about $700 \mu \mathrm{m}$, it is designed by CAD; the diameter of the micropores is ranging from 1 to $200 \mu \mathrm{m}$. The internal pores are mainly distributed uniform. The specimen is porosity and the pores are interconnectivity.

Figure 3(b) describes the internal structure of the sintered specimen after high temperature treatment. The crystalloid particles have nearly consistent size, and these particles conglutinate with each other, which form a near-net-shape. The near-net-shape has advantages for porosity and interconnectivity. The diameter is smaller than the diameter without high temperature treatment, its average size is about 20 to $100 \mu \mathrm{m}$. 


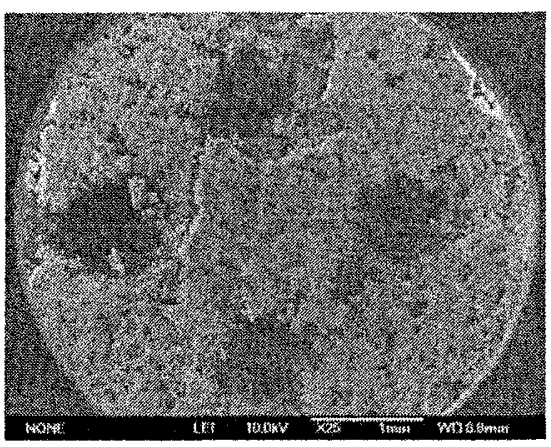

a before high temperature treatment

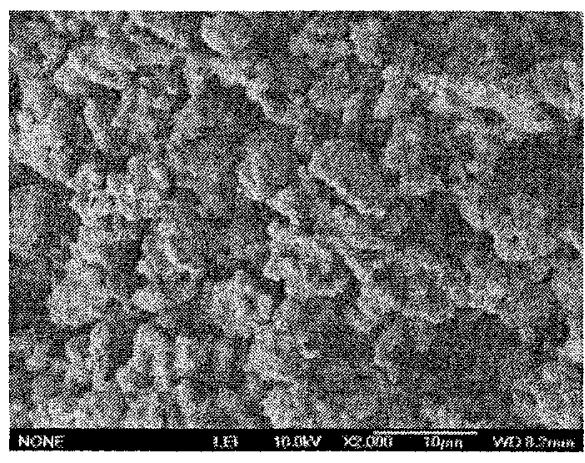

$\mathrm{b}$ after high temperature treatment

Fig. 3 SEM micrograph of scaffold

\subsection{Shrinkage assessment}

The conception of multihole bioceramic shrinkage was the ratio of volume change after sintering under high temperature to original volume. The relationship can be derived as:

$$
\mathrm{S}=\left(\mathrm{V}_{1}-\mathrm{V}_{2}\right) / \mathrm{V}_{1} \times 100 \%
$$

Where $S$ is the shrinkage of the scaffold, $V_{1}\left(\mathrm{~mm}^{3}\right)$ is the volume of original specimen, and $V_{2}\left(\mathrm{~mm}^{3}\right)$ is the volume of specimen after high temperature treatment.

Table 2 the shrinkage of scaffold

\begin{tabular}{|c|c|c|c|c|}
\hline \multicolumn{2}{|c|}{ High temperature treatment } & Specimen 1 & Specimen 2 & Specimen 3 \\
\hline \multirow{4}{*}{ Before } & $\mathrm{L}(\mathrm{mm})$ & 20 & 20 & 20 \\
\hline & $\mathrm{W}(\mathrm{mm})$ & 20 & 20 & 20 \\
\hline & $\mathrm{H}(\mathrm{mm})$ & 2.5 & 4 & 2 \\
\hline & $\mathrm{V}\left(\mathrm{mm}^{3}\right)$ & 1000 & 1600 & 800 \\
\hline \multirow{4}{*}{ After sinter } & $\mathrm{L}(\mathrm{mm})$ & 17.78 & 17.88 & 18.08 \\
\hline & $\mathrm{W}(\mathrm{mm})$ & 17.56 & 17.56 & 18.74 \\
\hline & $\mathrm{H}(\mathrm{mm})$ & 2.36 & 3.8 & 1.96 \\
\hline & $V\left(\mathrm{~mm}^{3}\right)$ & 736.83 & 1193.10 & 664.09 \\
\hline & & 26.32 & 25.43 & 16.99 \\
\hline
\end{tabular}

As the Table 2 shows that the shrinkage of the specimens is ranging from $16.99 \%$ to $26.32 \%$. While shrinkage usually occurred in the debinding step due to the collapse of voids created in the part as the polymer binders burned out. As a result, the degree of shrinkage was mainly determined by the amount of binder used. However shrinkage is a very complicated phenomenon dependent on a variety of parameters. The particle diameter has a strong effect on the shrinkage. The smaller the particles, the greater the 
shrinkage. Sintering time and sintering temperature are also important parameters. And degree of shrinkage is also dependent on the packing density, the particle shape and particle size distribution.

\section{CELL SEEDING}

The work of cell seeding was carried on Shanghai tissue engineering research center. Several specimens with an orthogonal interconnected pore design were manufactured as described previously and seeded with cells (figure 5). Firstly the specimens were moistened in ethanol. After the sterilization in an autoclave, the specimens were washed with Phosphate Buffered Solution (PBS). Then the specimens were cultured in Dulbecco's Modified Eagle Medium (DMEM) for one night. After the specimens sipped up, they were seeded with the bone mesenchymal cells and cultured in DMEM. The density of the cells is $2-5 \mathrm{million} / \mathrm{ml}$. Cells were cultured in an incubator at $37^{\circ} \mathrm{C}$ under humid atmosphere in $5 \% \mathrm{CO}_{2}$. Culture medium was changed every 3 days [10].

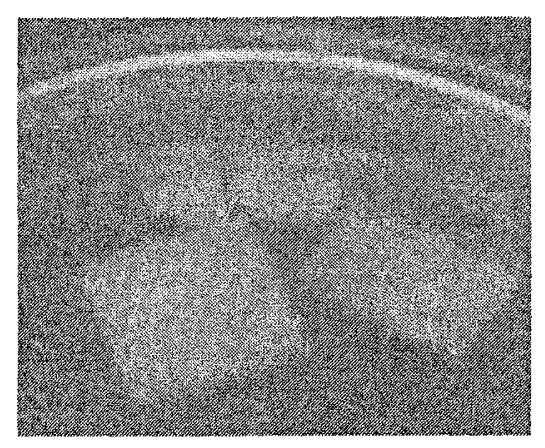

Fig.4 Scaffolds seeded with cells

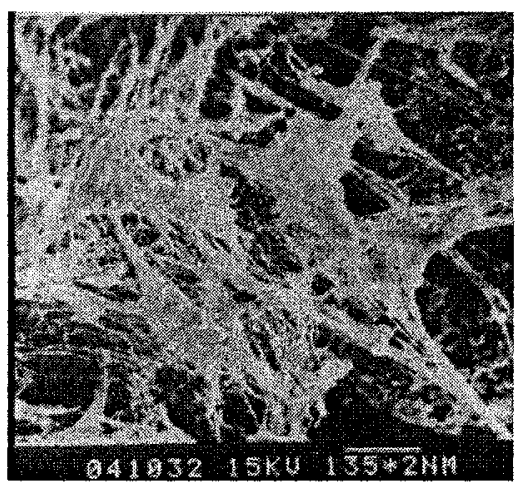

Fig.5 SEM micrograph of scaffold with attached bone mesenchymal cells

Figure 4 shows the scaffolds seeded with cells are cultured in DMEM. Figure 6 is the SEM micrograph of a scaffold specimen, which was covered with bone mesenchymal cells. Figure 5 shows that bone mesenchymal cells adhere and feel well on the specimen, that is to say, the scaffolds fabricated on SLS work well with cell.

\section{CONCLUSION}

The advantages of using SLS for bone tissue engineering scaffolds lie in the ability to control pore structure for biogenesis through the control of polymer contents and the ability to construct complex three-dimensional structure for bone tissue engineering applications. B -TCP scaffolds 
fabricated via SLS show great potential for replacement of bone tissues. The porosity of the specimens in our experiment achieved to $55 \%$. It's already content to the requirement of the bone tissue engineering. And with the growth of the new bone tissue, $\beta$-TCP scaffold, which was embedded in human body, will be biodegraded. While the shrinkage that ranging from $16.99 \%$ to $26.32 \%$ is high, so we have to offset these shrinkage in CAD modeling. As the cause of the shrinkage is complex, so it's a difficult point in our following work. In vivo results show that SLS-fabricated $\beta$-TCP scaffolds are propitious to the growth of bone mesenchymal cells.

\section{REFERENCES}

1. Patrick Jr CW, Mikos AG, Mcintire LV. Prospectus of tissue engineering. In: Patrick Jr $\mathrm{CW}$, Mikos AG, Mcintire LV, editors. Frontiers in Tissue Engineering, New York: Pergamon, 1998; 3 - 5.

2. Hutmacher DW. Scaffolds in tissue engineering bone and cartilage, Biomaterials, 2000;21:2529- 43 .

3. Zhongzhong Chen, Dichen Li, Bingheng Lu, Yiping Tang, Minglin Sun, Songfeng Xu. Fabrication of osteo-structure analogous scaffolds via fused deposition modeling, Scripta Materialia, 2005;52:157-161.

4. K.H. Tan, C.K. Chua, K.F. Leong, C.M. Cheah, P. Cheang, M.S. Abu Bakar, S.W. Cha. Scaffold development using selective laser sintering of polyetheretherketone hydroxyapatite biocomposite blends. Biomaterials, 2003;24:3115-3123.

5. Deckard CR. Part Generation by Layerwise Selective Sintering, MS thesis, Department of Mechanical Engineering, University of Texas at Austin; 1986.

6. Deckard, CR. Selective Laser Sintering, PhD dissertation, Department of Mechanical Engineering, University of Texas at Austin; 1988.

7. Das S, Hollister SJ, Flanagan C, Adewunmi A, Bark K, Chen C, Ramaswamy K, Rose D, Widjaja E. Freeform fabrication of nylon-6 tissue engineering scaffolds. Rapid Prototyping 2003;9(1):43- 9.

8. Tan KH, Chua CK, Leong KF, Cheah CM, Cheang P, Abu Bakar MS, Cha SW. Scaffold development using selective laser sintering of polyetheretherketone-hydroxyapatite biocomposite blends. Biomaterials, 2003;24(18):3115- 23.

9. Ernst Magnus Noah, Jingsong. Chen, Xiangyang Jiao, and Ingo Heschel, Impact of sterilization on the porous design and cell behavior in collagen sponges prepared for tissue engineering, Biomaterials, 2002;23: 2855-2861.) 